\title{
Studies on ectoparasites of stray dogs in Ismailia City
}

Asmaa M.I. Abuzeid ${ }^{1 *}$, Nahla H. Sallam $^{1}$, Eman M. Youssef ${ }^{1}$, Amal K. El-Gayar ${ }^{1}$, Ahmed A. Abdel Aal ${ }^{1}$,Hamdy M. ElGawady ${ }^{1}$

${ }^{1}$ Department of Parasitology, Faculty of Veterinary Medicine, Suez Canal University

${ }^{*}$ Corresponding author. Asmaa M.I. Abuzeid Tel.: +2 01094578925. E-mail address: asmaa_ibrahim@vet.suez.edu. eg

\begin{abstract}
:
In this study, a total of 50 stray dogs of different ages and sexes were captured from different areas of Ismailia City and examined for ectoparasites. The detected ectoparasites were six species of arthropods (one tick, three fleas, one louse, and one dipteran fly species). All the examined dogs were infested with at least one species of ectoparasites. The most prevalent ectoparasite was Ctenocephalides canis flea (100\%), followed by Rhipicephalus sanguineus tick (60\%), chewing lice (Heterodoxus spiniger) (46\%), Ctenocephalides felis flea (44\%), Hippobosca longipennis fly (16\%) and Echidnophaga gallinacea flea which was detected in $4 \%$ of examined dogs. Mixed ectoparasitic infestation with two or more ectoparasites was higher (84\%) than single infestation (16\%), with the most common combination (fleas and ticks) reaching $28 \%$. The prevalence of Heterodoxus spiniger was significantly higher $(p<0.01)$ in young dogs than adult ones, while Hippobosca longipennis prevalence was significantly higher $(p<0.05)$ in adult dogs than young ones. There was no significant difference $(p>0.05)$ in ectoparasite prevalence in relation to sexes. In conclusion, stray dogs in Ismailia City carry many ectoparasites that can be transmitted to companion dogs and act as vectors of many diseases affecting dogs and humans.
\end{abstract}

Key words: Prevalence, ectoparasites, stray dogs, Ismailia

\section{INTRODUCTION}

Ectoparasites are a common and important cause of skin diseases in dogs. These parasites can transmit various diseases and can cause hypersensitivity disorders in animals. Ectoparasites may also cause life-threatening anaemia in young and debilitated animals (Araujo et al., 1998). Some dog ectoparasites, such as fleas, can infest humans and lead to dermatitis and transmit vector-borne diseases (Scott et al., 2001). Ticks, after mosquitoes, are the second most important arthropods that may transmit pathogens like viruses, bacteria including rickettsia, protozoa (Babesiosis) and filarial nematodes (Onchocerciasis) to other animals and humans (Mosallanejad et al., 2011). Fleas are moderately specific, and the species Ctenocephalides canis, Ctenocephalides felis, Pulex irritans and Echidnophaga gallinacea (from poultry) are usually described in dogs (Alcaino et al., 2002). Different tick species infest dogs depending on the geographical area; however, one of the most widely distributed is Rhipicephalus sanguineus (Dantas-Torres, 2008). Dogs can be infested by lice, including the chewing lice, Heterodoxus spiniger and Trichodectes canis, and the sucking louse Linognathus setosus (González et al.,2004).
The present study aimed to determine the prevalence of ectoparasites of stray dogs in Ismailia City in relation to the age and sex of dogs.

\section{Materials AND Methods}

In this study, 50 stray dogs ( 23 male and 27 female) were captured within the boundaries of Ismailia City and examined for the presence of ectoparasites. The sex and age were recorded for each dog. The dogs under one year were classified as young $(n=20)$, and those over one year were considered adults $(n=30)$. The skin was palpatedand visually inspected for ectoparasites. All ticks were carefully removed to ensure that the mouthparts remained intact. Lice were detected either by visual examination or by hair brushing. Fleas were collected by putting the animal in closed plastic bag after spraying with insecticide. Hippobosca flies were collected using forcipes. All ectoparasites (i.e., fleas, lice, flies, and ticks) were transferred to a tube containing $70 \%$ ethanol for later identification. Deep ear swab specimens were obtained from both ears of all dogs. Deep and superficial skin scrapings were performed with mineral oil in suspected mite infections. The preserved specimens were washed to 
remove any adherent host tissue and were then placed inseparate sealed glass vials. The blood contents of ticks were evacuated using a syringe needle ventrally. The samples were put in Sodium hydroxide $10 \%$ to dissolve the chitinous undesirable materials for clearing during the microscopical examination. The specimens were washed several times with water, dehydrated with serial dilutions of alcohols (70, 80, 90, 95, and 100), and then cleared using xylene for 15-30 minutes. The samples were mounted on the glass slides using canada balsam, covered by a coverslip, left to dry, and examined under the light microscope (Hassan et al., 1958). Skin scrapings and ear swabs were placed in $10 \%$ potassium hydroxide and gently heated in a water bath to dissolve scales, crusts and hair or aural material. After that, the material was centrifuged, and the sediment was microscopically examined at X 40 for mites (Estrada-Pena and Venzal, 2007).

All arthropods were identified microscopically according to the diagnostic keys of Estrada-Pena and Venzal (2007) and Dantas-Torres and Otranto (2014). Chi-square test was used for the analysis of the categorical data, according to Snedecor and Cochran (1991), to determine significant association for age and sex and the prevalence of ectoparasites. Differences were considered significant at $(p \leq 0.05)$.

\section{RESULTS}

In the current study, the examined 50 stray dogs of different ages and sexes were infested with six ectoparasite species. The detected ectoparasites were one tick, three fleas, one louse, and one dipteran fly species.

\section{The Prevalence of ectoparasites:}

As shown in table (1), all the examined stray dogs were infested (100\%) with at least one species of ectoparasites. The most prevalent ectoparasite was Ctenocephalides canis fleas (100\%), followed by Rhipicephalus sanguineus tick (60\%) mostly on ears, abdomen, and around external genitalia, chewing lice (Heterodoxus spiniger) (46\%), Ctenocephalides felis fleas (44\%), Hippobosca longipennis fly(16\%), and Echidnophaga gallinacea flea (4\%).

2. The frequency of single and mixed ectoparasitic infestation:

Mixed ectoparasitic infestation with two or more ectoparasites was higher (84\%) than single infestation (fleas only) (16\%). The most common combination was fleas and ticks (28\%), followed by fleas, ticks, and lice (22\%) (Table 2).
Table 1: Prevalence of ectoparasites in stray dogs in Ismailia City

\begin{tabular}{lcc}
\hline Ectoparasite Species & $\begin{array}{c}\text { No. of infested/ } \\
\text { no. of examined }\end{array}$ & $\begin{array}{c}\text { Prevalence } \\
\%\end{array}$ \\
\hline Rhipicephalus sanguineus & $30 / 50$ & 60 \\
Ctenocephalides canis & $50 / 50$ & 100 \\
Ctenocephalides felis & $22 / 50$ & 44 \\
Echidnophaga gallinacean & $2 / 50$ & 4 \\
Heterodoxus spiniger & $23 / 50$ & 46 \\
Hippobosca longipennis & $8 / 50$ & 16 \\
Total Prevalence & $50 / 50$ & 100 \\
\hline
\end{tabular}

Table 2: The frequency of single and mixed ectoparasitic infestation in stray dogs in Ismailia City

\begin{tabular}{lcc}
\hline \multicolumn{1}{c}{ Ectoparasites } & $\begin{array}{c}\text { No. of infested/no. } \\
\text { of examined }\end{array}$ & $\%$ \\
\hline Single infestation (fleas only) & $8 / 50$ & 16 \\
Mixed infestation & $42 / 50$ & 84 \\
Fleas and ticks & $14 / 50$ & 28 \\
Fleas and lice & $9 / 50$ & 18 \\
Fleas, ticks and lice & $11 / 50$ & 22 \\
Fleas, ticks and Hippobosca & $5 / 50$ & 10 \\
longipennis fly & & \\
Fleas, lice and Hippobosca & $3 / 50$ & 6 \\
longipennis fly & & \\
\hline
\end{tabular}

3. The prevalence of different ectoparasites in relation to the age and sex:

As shown in tables $3 \& 4$, Ctenocephalides canis was recovered from all young, adult, male and female dogs. There was no significant difference $(p>0.05)$ in the prevalence of Rhipicephalus sanguineus, C. felis and Echidnophaga gallinacea in relation to age. There was a highly significant difference at $(p<0.01)$ in the prevalence of Heterodoxus spiniger between young and adult dogs. Hippobosca longipennis was significantly higher $(p<0.05)$ in adult dogs $(26.7 \%)$ than young $(0.0 \%)$ by using the Chisquare test. Moreover, there was no significant difference in the prevalence of all detected ectoparasites in relation to sex.

\section{Discussion}

Here, all dogs had at least one species of ectoparasites (total prevalence 100\%). This result agreed with that of González et al. (2004) (100\%) in Argentina and Kumsa \& Mekonnen (2011) (99.5\%) in Southern Ethiopia. However, total ectoparasites prevalence in this study was higher than that reported by Chee et al. (2008) (45.6\%) in the Republic of Korea, Dantas-Torres et al. (2009) (70.7\%) in North-eastern Brazil, and Costa et al. (2013) (63\%) in North-eastern Brazil. The only detected tick species 
Table 3: The prevalence of different ectoparasites in relation to age

\begin{tabular}{|c|c|c|c|c|c|}
\hline Ectoparasites & Age & No. of infested/ no. of examined & Prevalence (\%) & $\mathrm{x}^{2}$ & p-value \\
\hline \multirow[t]{2}{*}{ Rhipicephalus sanguineus } & Young & $10 / 20$ & 50.0 & 0.78 & 0.38 \\
\hline & Adult & $20 / 30$ & 66.7 & & \\
\hline \multirow[t]{2}{*}{ Ctenocephalides canis } & Young & $20 / 20$ & 100.0 & NA & NA \\
\hline & Adult & $30 / 30$ & 100.0 & & \\
\hline \multirow[t]{2}{*}{ Ctenocephalides felis } & Young & $8 / 20$ & 40.0 & 2.47 & 0.12 \\
\hline & Adult & $14 / 30$ & 46.7 & & \\
\hline \multirow[t]{2}{*}{ Echidnophaga gallinacea } & Young & $0 / 20$ & 0.0 & 0.195 & 0.66 \\
\hline & Adult & $2 / 30$ & 6.7 & & \\
\hline \multirow[t]{2}{*}{ Heterodoxus spiniger } & Young & $19 / 20$ & 95.0 & 29.02 & $0.00^{* *}$ \\
\hline & Adult & $4 / 30$ & 13.3 & & \\
\hline \multirow[t]{2}{*}{ Hippobosca longipennis } & Young & $0 / 20$ & 0.0 & 4.52 & $0.03^{*}$ \\
\hline & Adult & $8 / 30$ & 26.7 & & \\
\hline
\end{tabular}

* Significant difference $p \leq 0.05, * *$ highly significant difference $p \leq 0.01$, NA: not applicable

Table 4: The prevalence of different ectoparasites in relation to sex

\begin{tabular}{|c|c|c|c|c|c|}
\hline Ectoparasites & Sex & No. of infested/ no. of examined & Prevalence (\%) & $\mathrm{x}^{2}$ & $\overline{p \text {-value }}$ \\
\hline \multirow[t]{2}{*}{ Rhipicephalus sanguineus } & Male & $10 / 23$ & 43.5 & 3.65 & 0.06 \\
\hline & Female & $20 / 27$ & 74.1 & & \\
\hline \multirow[t]{2}{*}{ Ctenocephalides canis } & Male & $23 / 23$ & 100.0 & NA & NA \\
\hline & Female & $27 / 27$ & 100.0 & & \\
\hline \multirow[t]{2}{*}{ Ctenocephalides felis } & Male & $10 / 23$ & 43.5 & 0.05 & 0.83 \\
\hline & Female & $12 / 27$ & 44.4 & & \\
\hline \multirow[t]{2}{*}{ Echidnophaga gallinacea } & Male & $2 / 23$ & 8.7 & 0.71 & 0.40 \\
\hline & Female & $0 / 27$ & 0.0 & & \\
\hline \multirow[t]{2}{*}{ Heterodoxus spiniger } & Male & $9 / 23$ & 39.1 & 0.38 & 0.54 \\
\hline & Female & $14 / 27$ & 51.9 & & \\
\hline \multirow[t]{2}{*}{ Hippobosca longipennis } & Male & $3 / 23$ & 13.0 & 0.02 & 0.89 \\
\hline & Female & $5 / 27$ & 18.5 & & \\
\hline
\end{tabular}

NA: not applicable

was Rhipicephalus sanguineus with a total prevalence of $60 \%$. This result was nearly similar to El-Gayar (2005) (66.7\%) in Ismailia City. A lower prevalence was recorded by Bahrami \& Delpisheh (2010) (27.5\%) in Iran, Troyo et al. (2012) (18\%) in Costa Rica and Dumitrache et al. (2014) (0.2\%) in Romania. On the contrary, a higher prevalence was reported by González et al. (2004) (73\%) in Argentina, Klimpel et al. (2010) (100\%) and Heukelbach et al. (2012) (89.7\%) in Brazil. Rhipicephalus sanguineus was probably a native tick of Africa (Soulsby, 1982), with the most widespread distribution among all tick species infesting dogs (Walker et al., 2000). Adults of this threehost tick feed almost exclusively on dogs. However, all development stages can be occasionally found on other wild (e.g. rodents) and domesticated mammalian hosts, including humans (Dantas-Torres, 2008). The total prevalence of flea infestation was $100 \%$. This result was higher than that of González et al. (2004) (15.7\%) in Argentina, El-Gayar (2005) (53.3\%) in Ismailia City, Rinaldi et al. (2007) (17.9\%) in Italy, and Jamshidi et al. (2012) (29.4\%) in Iran.
The prevalence of Ctenocephalides canis flea was $100 \%$ of examined dogs during this study. This result was higher than reports by Chee et al. (2008) (6.8\%), Bahrami \& Delpisheh (2010) (29.5\%) and Kumsa \& Mekonnen (2011) (73.8\%). The prevalence of $C$. felis (44\%) was similar to Dantas-Torres et al. (2009) (43.9\%) while higher than recorded by Aldemir (2007) (4.17\%), Bahrami \& Delpisheh (2010) (6.1\%) and Klimpel et al. (2010) (17.4\%). On the contrary, a higher prevalence was recorded by Tavassoli et al. (2010) (67.5\%), Kumsa \& Mekonnen (2011) (82.9\%) and Troyo et al. (2012) (83\%). Sticktight flea, Echidnophaga gallinacea was recorded in $4 \%$ of examined dogs. It was previously reported in dogs by Durden et al. (2005) in Georgia, U.S.A., Gracia et al. (2008) (0.13\%) in Spain, and Ŝlapeta et al. (2011) in Western Australia. Also, this flea species had been recorded from dogs by Amin (1966) in the Nile Valley and Delta. The sticktight flea, E. gallinacean, parasitizes birds (especially chickens) and certain mammals (Hopkins \& Rothschild, 1953; Dryden, 1993 and Durden \& Traub, 2002). Although dogs may have acquired these fleas as 

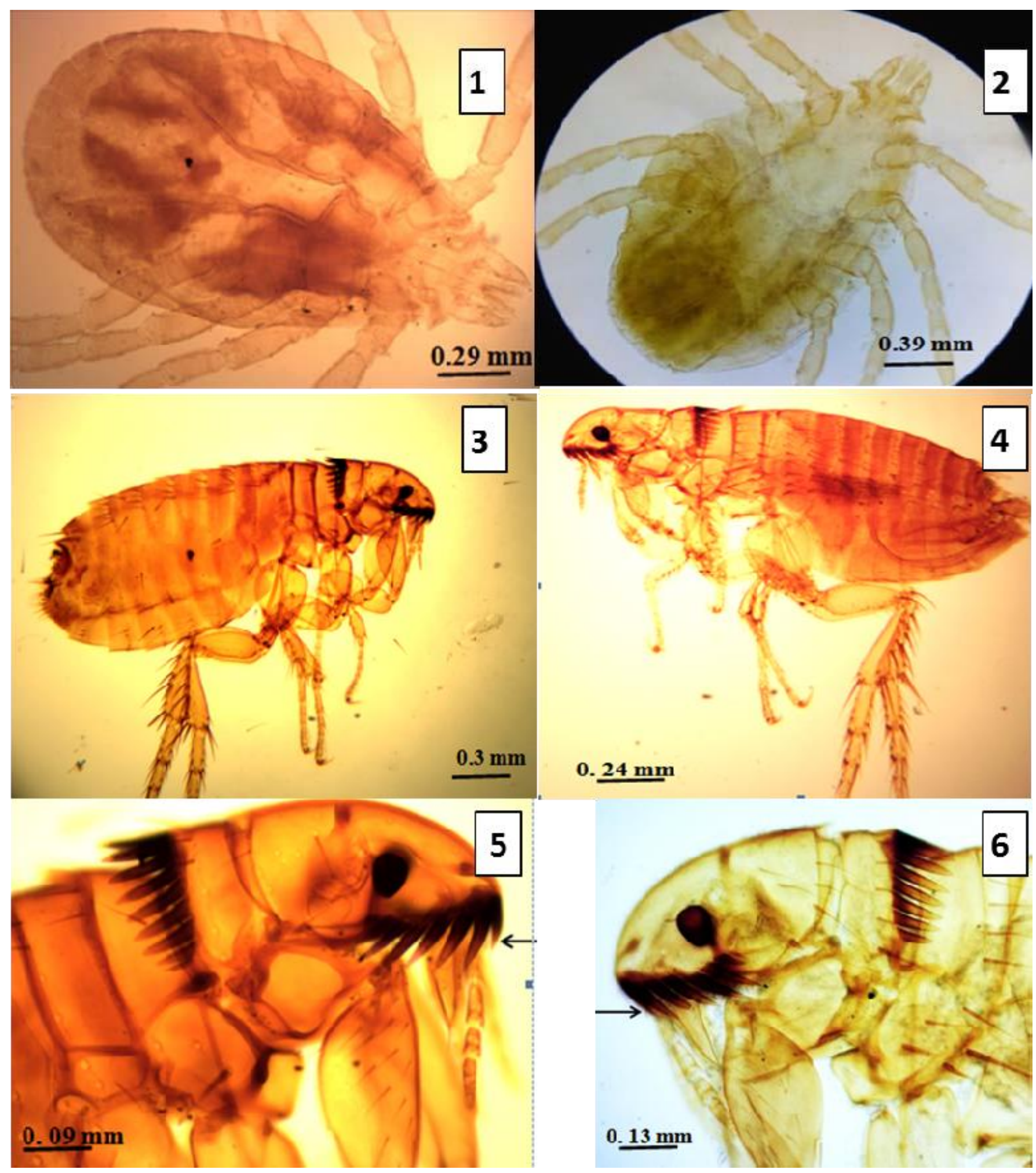

Figure 1: Rhipicephalus sanguineus male (x4)

Figure 2: Rhipicephalus sanguineus female (x4) (arrow showing spurs on the base of capitulum)

Figure 3: Ctenocephalides canis female $(x 4)$

Figure 4: Ctenocephalides canis male $(x 4)$

Figure 5: Ctenocephalides canis head $(x 10)$ (arrow showing spine 1 of genal ctenidium shorter than spine 2)

Figure 6: Ctenocephalides felis head (x10) (arrow showing spine 1 of genal ctenidium nearly equal to spine 2). 


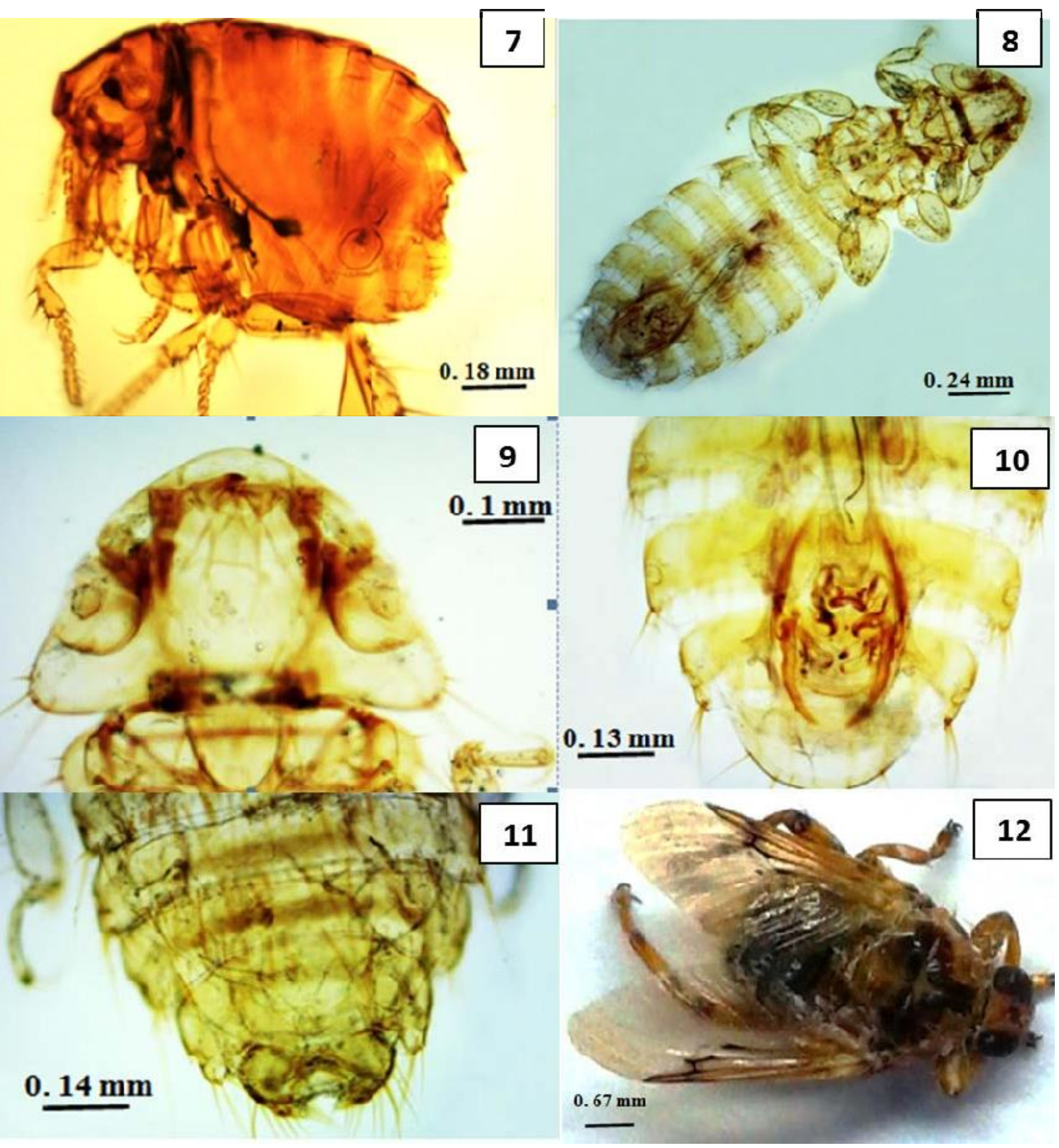

Figure 7: Echidnophaga gallinacea female ( $\mathrm{x} 4)$

Figure 8: Heterodoxus spiniger male $(\mathrm{x} 4)$

Figure 9: Heterodoxus spiniger head (x10), sub-triangular with two palpal processes (arrows) behind two maxillary palps (arrowheads) Figure 10: Heterodoxus spiniger male posterior end $(x 10)$

Figure 11: Heterodoxus spiniger female posterior end $(x 10)$

Figure 12: Hippobosca longipennis fly adult 
temporarily free-living ectoparasites from vegetation (Durden \& Traub, 2002), it is more likely that these fleas were acquired during hunting activities by certain individual dogs. Dogs in various parts of the world can acquire transient flea infestations through their contacts with birds, rodents, lagomorphs, insectivores, carnivores, or other endothermic vertebrates (Hatch \& Dooge, 1986; Franc et al., 1998). Only one louse species was recorded in the present study (Heterodoxus spiniger), with a prevalence of $46 \%$. This result was nearly similar to that of Rao et al. (2013) (43.27\%) in India, while lower than that reported by Klimpel et al. (2010) (67.4\%) in Brazil. On the contrary, a lower prevalence was recorded by El-Gayar (2005) (33.3\%) in Ismailia City, Dantas-Torres et al. (2009) (22\%) in Brazil, Kumsa \& Mekonnen (2011) (4\%) in Southern Ethiopia, Troyo et al. (2012) (10\%) on the Caribbean slope of Costa Rica, and Sultan \& Khalafalla (2014) (20\%) in Kafr El-Sheikh City. In Egypt, Amin \& Madbouly (1973) recorded that Heterodoxus spiniger prevalence rate reached $5 \%$. This increased prevalence in Egypt over the years indicates the adaptation of $H$. spiniger to the local dogs explained by the suitability of the climate and availability of hosts (Sultan \& Khalafalla, 2014).

The recovery of Hippobosca longipennis fly from $16 \%$ of examined dogs during this study agreed with the result of Vanak et al. (2007) (16\%) in Maharastra - India, and the early report of Amin \& Madbouly (1973) (18\%) in the Nile Valley and Delta of Egypt. Hippobosca sp. fly was previously recorded in dogs in Iran by Mosallanejad et al. (2011), with a lower prevalence (1.59\%). Wild and domestic canids represent the preferred primary hosts for Hippobosca longipennis. Concerning the public health significance of this ectoparasite, humans are occasionally bitten by the family Hippoboscidae flies (Bequaert, 1930).

In our opinion, the variation in the prevalence of ectoparasites can be ascribed to differences in host habitat/climatic factors and the sampling period. Peak prevalence of ectoparasites usually occurs during the warm, dry months.

Current results revealed that mixed ectoparasitic infestation with two or more ectoparasites (84\%) was higher than a single infestation. This result was lower than the reports of González et al. (2004) (96.6\%) in Argentina, El-Gayar (2005) (93.3\%) in Ismailia City, while higher than the result of Troyo et al. (2012) (66\%) in Costa Rica. The most common combination in our study was (fleas and ticks) similar to El-Gayar (2005) and Costa et al. (2013), this disagreed with Troyo et al. (2012) (the most common combination was Ctenocephalides felis and Pulex simulans) and González et al. (2004) (triple infestation [ticks-fleas-lice] was the most common combination). On the contrary, Chee et al. (2008) in Korea, Dantas-Torres et al. (2009) in Brazil, Mosallanejad et al. (2011) in Iran and Jamshidi et al. (2012) in Iran recorded that single infestation was higher than mixed infestation, including. There was no significant difference in the prevalence of Rhipicephalus sanguineus, Ctenocephalides felis and Echidnophaga gallinacea in relation to age. This result was consistent with previous reports (Dantas-Torres et al., 2009; Kumsa \& Mekonnen, 2011; Mosallanejad et al., 2011). The prevalence of Heterodoxus spiniger was significantly higher in young dogs than adults. This result agreed with Chee et al. (2008) but disagreed with Rao et al. (2013), who reported that dogs above 19 months years old were infested with $45.28 \% \mathrm{H}$. spiniger, followed by younger ones (44.34\%). Dogs less than one-year-old were more susceptible to ectoparasite infestations, owing to their constant exposure to carrier mothers (Scott, 1979). Moreover, young dogs are less resistant than adults due to their immature immune systems. Hippobosca longipennis was significantly higher in adult dogs (26.7\%) than young $(0.0 \%)$. This result might be explained by the fact that adult dogs have more roaming behaviour than young ones.

In this study, there was no significant difference in the prevalence of ectoparasites in relation to the sex of dogs. This finding agreed with previous reports (Dantas-Torres et al., 2009; Kumsa \& Mekonnen, 2011; Mosallanejad et al., 2011). Although the differences were not statistically significant, all ectoparasitic infestation rates were higher in females than in males except Echidnophaga gallinacea. This observation agreed with other studies (Arijo et al., 2007; Tavassoli et al., 2010 and Rao et al., 2013), who have also reported a greater susceptibility of females for ectoparasites. In addition, confining of females during the reproductive period could favour re-infestations by ectoparasites (Aldemir, 2007). The prevalence of Echidnophaga gallinacea was higher in males $(8.7 \%)$ than females $(0.0 \%)$. This result might be due to hormonal factors and sex-associated behaviours, such as roaming, to encounter birds. In conclusion, stray dogs in Ismailia City carried many ectoparasites that might act as vectors of many diseases affecting dogs and humans. 


\section{REFERENCES}

Alcaino, H. A.; Gorman, T.R. and Alcaíno, R. (2002): Flea species from dogs in three cities of Chile. Vet. Parasitol., 105: 261-265.

Aldemir, O.S. (2007): Epidemiological study of ectoparasites in dogs from Erzurum region in Turkey. Revue Méd. Vét., 158(3): 148-151.

Amin, O.M. (1966): The fleas (Siphonaptera) of Egypt: distribution and seasonal dynamics of fleas infesting dogs in the Nile valley and delta. J. Med. Entomol., 3(3): 293298.

Amin, O.M. and Madbouly, M. (1973): Distribution and seasonal dynamics of a tick, a louse fly, and a louse infesting dogs in the Nile valley and delta of Egypt. J. Med. Entomol., 10: 295-298.

Araujo, F.R.; Silva, M.P.; Lopes, A.A.; Ribeiro, O.C.; Pires, P.P.; Carvalho, C.M.; Balbuena, C.B.; Villas, A.A. and Ramos, J.K. (1998): Severe cat flea infestation of dairy calves in Brazil. Vet. Parasitol., 80(1): 83-86.

Arijo, A.G.; Omani, K.T. and Rajput, Z.I. (2007):

Ctenocephalides felis in dogs and cats in Tandojam region. Pak. J. Biol. Sci., 10(15): 2579-2582.

Bahrami, A.M. and Delpisheh, A. (2010): Common Ectoparasite Species of Domestic Dogs in Western Iran. World Applied Sciences Journal, 8(10): 1277-1281.

Bequaert, J. (1930): Notes on Hippoboscidae 2. The subfamily Hippoboscinae. Psyche (Stuttg), XXXVII, Pp: 303 $-326$.

Chee, J.-H.; Kwon, J.-K.; Cho, H.-S.; Cho, K.-O.; Lee, Y.-J.; Abd El-Aty, A.M. and Shin, S.-S. (2008): A Survey of Ectoparasite Infestations in Stray Dogs of Gwang-ju City, Republic of Korea. Korean J. Parasitol., 46(1): 23-27.

Costa, A.P.; Silva, A.B; Costa, F.B.; Xavier, G.S.; Martins, T.F.; Labruna, M.B. and Guerra, R.M. (2013): A survey of ectoparasites infesting urban and rural dogs of Maranhão state, Brazil. J. Med. Entomol., 50(3): 674-678.

Dantas-Torres, F. (2008): Ixodidae. The brown dog tick, Rhipicephalus sanguineus (Latreille, 1806) (Acari:): from taxonomy to control. Vet. Parasitol., 152(3-4): 173-185. Dantas-Torres, F. and Otranto, D. (2014): Dogs, cats, parasites, and humans in Brazil: opening the black box. Parasites \& Vectors, 7: 22.

Dantas-Torres, F.; Melo, M.F.; Figueredo, L.A. and Brandão-Filho, S.P. (2009): Ectoparasite infestation on rural dogs in the municipality of São Vicente Férrer, Pernambuco, Northeastern Brazil. Rev. Bras. Parasitol. Vet., 18(3): 75-77.

Dryden, M.W. (1993): Biology of fleas of dogs and cats. Comp. Cont. Educ. Pract. Vet., 15: 569-579.

Dumitrache, M.O.; Kiss, B.; Dantas-Torres, F.; Latrofa, M.S.; D'Amico, G.; Sándor, A.D. and Mihalca, A.D. (2014): Seasonal dynamics of Rhipicephalus rossicus attacking domestic dogs from the steppic region of southeastern Romania. Parasites \& Vectors, 7: 97.

Durden, L.A. and Traub, R. (2002): Fleas (Siphonaptera). In: Mullen, G., Durden, L. (Eds.), Medical and Veterinary
Entomology. Academic Press/Elsevier Science, San Diego, Pp: 103-125.

Durden, L.A.; Judy, T.N.; Martin, J.E. and Spedding, L.S. (2005): Fleas parasitizing domestic dogs in Georgia, U.S.A.: species composition and seasonal abundance. Vet. Parasitol., 130(1-2): 157-162.

El-Gayar, A. K. (2005): The prevalence of some parasites of stray dogs in Ismailia City. EVMSPJ., 11(2): 383-400.

Estrada-Pena, A. and Venzal, J. M. (2007): Climate Niches of Tick Species in the Mediterranean Region: Modeling of Occurrence Data, Distributional Constraints, and Impact of Climate Change. J. Med. Entomol., 44(6): 1130-1138.

Franc, M.; Choquart, P. and Cadiergues, M.C. (1998): Species of fleas found on dogs in France. Rev. Med. Vet., 149: 135-140.

González, A.; Castro, D.C. and González, S. (2004): Ectoparasitic species from Canis familiaris (Linné) in Buenos Aires province, Argentina. Vet. Parasitol., 120(12): 123-129.

Gracia, M.J.; Calvete, C.; Estrada, R.; Castillo, J.A.; Peribáñez, M.A. and Lucientes, J. (2008): Fleas parasitizing domestic dogs in Spain. Vet. Parasitol., 151(24): 312-319.

Hassan, A.A.; Habib, A. and Issa, G.I. (1958): The hard ticks of Egypt (Arthropoda;Acarina; Ixodidae). J. Egypt. Vet. Med.Assoc., 18: 3-20.

Hatch, C. and Dooge, D.J. (1986): Fleas on hedgehogs and dogs. Vet. Rec., 119: 162.

Heukelbach, J.; Frank, R.; Ariza, L.; de Sousa Lopes, I.; de Assis e Silva, A.; Borges, A.C. ; Limongi, J.E. ; de Alencar, C.H.M. and Klimpel, S. (2012): High prevalence of intestinal infections and ectoparasites in dogs, Minas Gerais State (Southeast Brazil). Parasitol. Res., 111: 19131921.

Hopkins, G.H.E. and Rothschild, M. (1953): An illustrated catalogue of the Rothschild Collection of fleas (Siphonaptera) in the British Museum (Natural History) with keys and short descriptions for the identification of families, genera, species and subspecies, vol. I. Tungidae and Pulicidae. Trustees of the British Museum (Natural History), London.

Jamshidi, S.; Maazi, N.; Ranjbar-Bahadori, S.; Rezaei, M.; Morakabsaz, P. and Hosseininejad, M. (2012): A survey of ectoparasite infestation in dogs in Tehran, Iran. Rev. Bras. Parasitol. Vet., 21(3): 326-329.

Klimpel, S.; Heukelbach, J.; Pothmann, D. and Rückert, S. (2010): Gastrointestinal and ectoparasites from urban stray dogs in Fortaleza (Brazil): high infection risk for humans? Parasitol. Res., 107(3): 713-719.

Kumsa, B.E. and Mekonnen, S. (2011): Ixodid ticks, fleas and lice infesting dogs and cats in Hawassa, Southern Ethiopia. Onderstepoort J. Vet. Res., 78(1): 326.

Mosallanejad, B.; Alborzi, A.R. and Katvandi, N. (2011): A Survey on Ectoparasite Infestations in Companion Dogs of Ahvaz District, South-west of Iran. Arthropod-Borne Dis., 6 (1): 70-78. 
Rao, R.M.; Chandra, S. and Singh, S.K. (2013): Occurrence of phthirapteran ectoparasite parasitizing on domestic dogs, Canis familiaris (Linne) in Jaunpur district (U.P.). Journal of Applied and Natural Science, 5(1): 207-212. Rinaldi, L.; Spera, G.; Musella, V.; Carbone, S.; Veneziano, V.; lori, A. and Cringoli, G. (2007): A survey of fleas on dogs in southern Italy. Vet Parasitol., 148(3-4): 375-378. Scott, D.W. (1979): Canine demodicosis. Vet. Clin. North. Am., 9: 79-92.

Scott, D.W.; Miller, W.H. and Griffin, C.E. (2001): Muller and Kirk's Small Animal Dermatology. Sixth Ed. WB Saunders; Philadelphia, U.S.A.

Ŝlapeta, J.; King, J.; McDonell, D.; Malik, R.; Homer, D.; Hannan, P. and Emery, D. (2011): The cat flea (Ctenocephalides $f$. felis) is the dominant flea on domestic dogs and cats in Australian Veterinary Practices. Vet. Parasitol., 180: 383-388.

Snedecor, G.W. and Cochran, W.G. (1991): Statistical Methods (Eighth Ed.). Journal of the American Statistical Association, 86(415): 834.

Soulsby, E.J.L. (1982): Helminths, arthropods, and protozoa of domesticated animals. Seventh Ed. Lea \& Febiger, Philadelphia.
Sultan, K. and Khalafalla, R.E. (2014): First record of chewing louse Heterodoxus spiniger (Insecta, Phthiraptera, Boopidae) on stray dogs from northern region of Egypt. Tropical Biomedicine, 31(2): 378-380.

Tavassoli, M.; Ahmadi, A.; Imani, A.; Ahmadiara, E.; Javadi, S. and Hadian, M. (2010): Survey of Flea Infestation in Dogs in Different Geographical Regions of Iran. Korean J. Parasitol., 48(2): 145-149.

Troyo, A.; Calderón-Arguedas, Ó.; Alvarado, G.; VargasCastro, L.E. and Avendaño, A. (2012): Ectoparasites of dogs in home environments on the Caribbean slope of Costa Rica. Rev. Bras. Parasitol. Vet., 21(2): 179-183. Vanak, A.T.; Belsare, A.V. and Gompper, M.E. (2007): Survey of disease prevalence in free-ranging domestic dogs and possible spill-over risk for wildlife - A case study from the Great Indian Bustard Sanctuary, Maharastra India. The Rufford Small Grants Foundation, U.K.: 1-13.

Walker, Jane B.; Keirans, J.E. and Horak, I.G. (2000): The genus Rhipicephalus sanguineus (Acari: Ixodidae) a guide to the brown ticks of the world. Cambridge: Cambridge University Press. 